\title{
Correction to: Phase Ib/ll study of gemcitabine, nab-paclitaxel, and pembrolizumab in metastatic pancreatic adenocarcinoma
}

\author{
Glen J. Weiss ${ }^{1,2} \cdot$ Lisa Blaydorn ${ }^{1} \cdot J^{\prime}$ ulia Beck ${ }^{3} \cdot$ Kirsten Bornemann-Kolatzki $^{3} \cdot$ Howard Urnovitz $^{3} \cdot$ Ekkhard Schütz $^{3}$. \\ Vivek Khemka ${ }^{1,4}$
}

Published online: 24 April 2019

(C) Springer Science+Business Media, LLC, part of Springer Nature 2019

\section{Correction to: Invest New Drugs (2018) 36:96-102 https://doi.org/10.1007/s10637-017-0525-1}

The authors would like to note an error in Figures 1 and 2 of this paper. The graph in Figure 1 incorrectly reflected the overall survival (OS), when it should have displayed the progression-free survival (PFS). The caption and median PFS values were correct. It was also noted that the upper value for the $95 \% \mathrm{CI}$ had an error in both figures. Both graphs have been regenerated using the published PFS and OS data presented in Table 2 and the corrected 95\% CIs are included. These changes do not impact the overall results of the data or the conclusions presented in the publication. We sincerely apologize for this oversight.

Publisher's note Springer Nature remains neutral with regard to jurisdictional claims in published maps and institutional affiliations.

The online version of the original article can be found at https://doi.org/ 10.1007/s10637-017-0525-1

Glen J. Weiss

drglenweiss@outlook.com

1 Western Regional Medical Center, Cancer Treatment Centers of America, Goodyear, AZ, USA

2 Present address: University of Arizona College of Medicine-Phoenix, Phoenix, AZ, USA

3 Chronix Biomedical, Göttingen, Germany

4 Present address: Virginia G. Piper Cancer Center, Scottsdale, AZ, USA

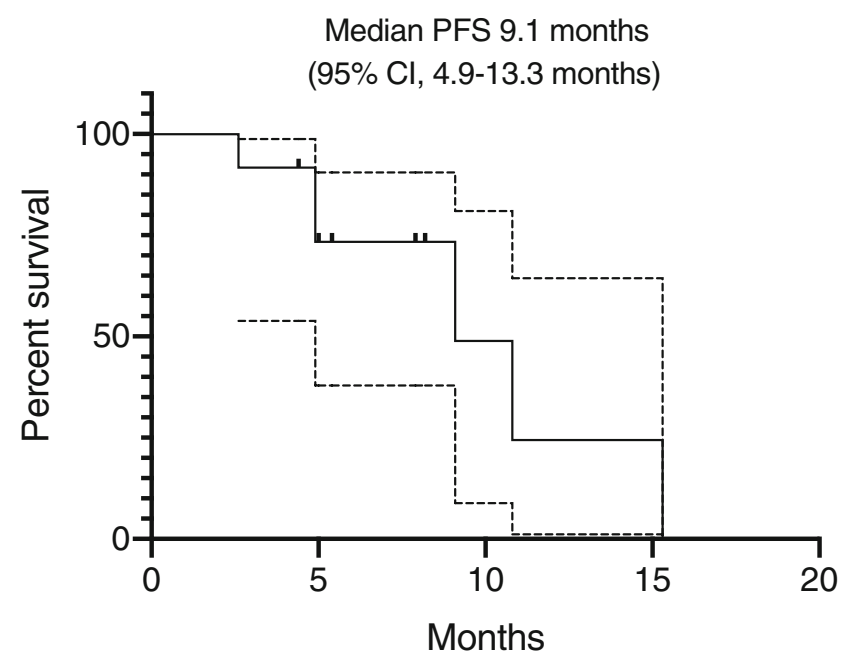

Fig. 1 PFS for chemotherapy treatment naïve PDAC $(n=12)$. The solid line shows PFS. The hashed line shows the 95\% CI (confidence interval) for the curve

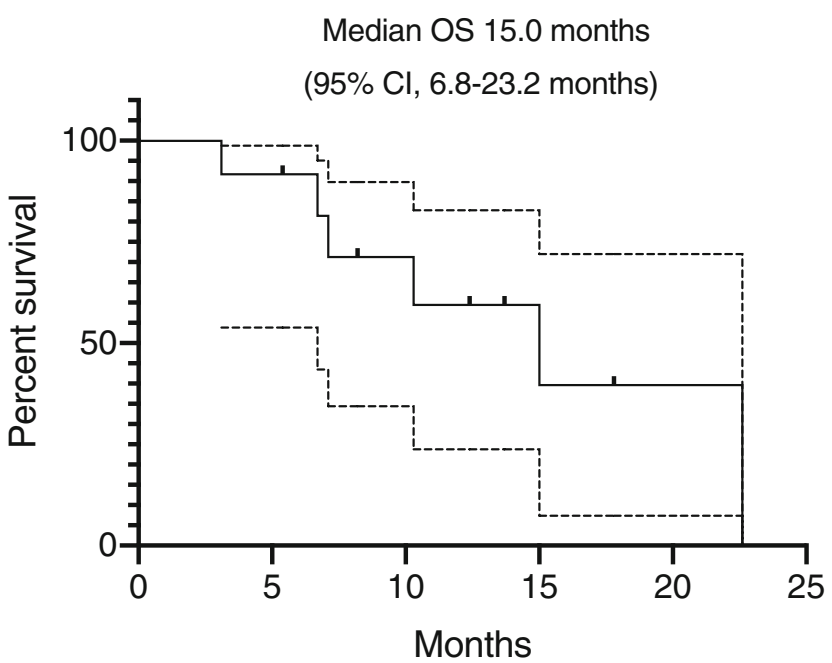

Fig. 2 OS for chemotherapy treatment naïve PDAC $(n=12)$. The solid line shows OS. The hashed line shows the $95 \%$ CI for the curve 